\title{
Parental Partnership Program to Improve Resources for Pediatric Sickle Cell Care
}

\author{
Krystle Stone and Betty S Pace*
}

Department of Pediatrics, Augusta University, Augusta, GA

*Corresponding author: Betty S Pace, Department of Pediatrics, Augusta University, Augusta, Georgia

\begin{tabular}{|c|c|}
\hline ARTICLE INFO & Abstract \\
\hline Received: 慧 October 08, 2020 & $\begin{array}{l}\text { Objective: The organization Parent to Parent (P2P) of Georgia is a community } \\
\text { organization that offers parental support as a core resource for families with children }\end{array}$ \\
\hline Published: 閟 December 11, 2020 & $\begin{array}{l}\text { who have special health care needs, disability, and mental health diagnoses. This study } \\
\text { was conducted to launch a P2P program at Children's Hospital of Georgia. }\end{array}$ \\
\hline
\end{tabular}

Citation: Krystle Stone, Betty S Pace. Parental Partnership Program to Improve Resources for Pediatric Sickle Cell Care. Biomed J Sci \& Tech Res 32(3)-2020. BJSTR. MS.ID.005265.

Methods: A Parent Partner was assigned to the Pediatric Sickle Cell Clinic at CHOG to collect information during routine visits. The Parent Partner identified resources such as social security administration, school forms, and resources in local community. Information was provided to the families during clinic visits and/or by mail, telephone, and email.

Results: During the 3-year observation period, there were 545 cases completed at Children's Hospital of Georgia and 635 referrals by the Parent Partners to different services. The most common request was social security administrative resources for supplemental security income. We proved services at: Level 1 (0-10 minutes), $\mathrm{n}=61$ (11.9\%); Level 2 (11-15 minutes), $\mathrm{n}=183$ (33.58\%); Level 3 (16-30 minutes) $\mathrm{n}=245$ (44.95\%); Level 4 (31-45 minutes), $n=49$ (9.00\%); and Level 5 ( $>45$ minutes) $n=7$ (1.28\%). There were 104 follow up calls, which confirmed the families were becoming more independent following up resources leads. In additional, three Supporting Parents were certified and trained in communication and providing resources to other families and a Parent/Patient Support Group was established.

Conclusion: This is the first P2P program for sickle cell disease. The program was highly accepted by families and they acknowledged the importance of self-awareness and education, and independence with providing care of their children. The P2P program improved the quality of care, and health for families and children with sickle cell disease.

\section{Introduction}

Parent to Parent of Georgia (P2P) is a national nonprofit organization that promotes excellence in $\mathrm{P} 2 \mathrm{P}$ programs across the nation. P2P programs have been providing information and referral support for families of children with special health care needs, disabilities, or mental health diagnoses since the 1970s. P2P believes that strength and power come when connecting parents of children with any illness. Their mission and vision are built from quality support, fully-functioning, and integrity [1]. Sickle cell anemia is an autosomal recessive inherited blood disorder caused by a single point mutation in the $\beta$-globin gene on chromosome 11. There are approximately 100,000 people living with sickle cell disease (SCD) in the United States and millions worldwide.
Individuals with homozygous SCD make abnormal hemoglobin S protein, which undergoes polymerization under hypoxia conditions producing long rod-like structures in red blood cells, i.e. sickle cells. This sickled shape leads to vaso-occlusion by blocking small blood vessels to deprive vital organs of oxygen causing periodic acute pain episodes, other clinical complications and early death [2]. Due to the chronic nature of SCD and the demands required of families, which impacts quality of life, some parents become overwhelmed after receiving newborn screening test results. To help caregivers, we identified community resources to improve medical outcomes. The objective of this quality improvement evaluation was to determine if face-to-face education using Parent Partners would 
improve health care delivery to children with SCD. We observed improved compliance based on information the parents and care givers submitted during clinic visits.

\section{Methods}

Parent Partner Collaboration: A partnership was established between the Augusta University Pediatric Comprehensive Sickle Cell Program at Children's Hospital of Georgia (CHOG) and the Parent to Parent (P2P) of Georgia. This work did not require IRB approval since it falls under quality improvement of care. All patient information was handle under HIPPA requirements. After intense training by P2P for $\sim 6$ weeks, two certified Parent Partners were assigned to CHOG during the evaluation period from October 2014 to September 2017. The P2P organization provided additional onsite training for CHOG hematology faculty and staff.

P2P Intake Interview: During the clinic visit, the Parent Partner met with patient and caregiver to complete the P2P of Georgia Referral Form and specific needs of the family was recorded during the interview. These data were entered into a secure database maintained by P2P; information related to social security administration, school forms, and community resources were identified. Information was provided to families during visits and/or by mail, telephone, and email. Insurance and employment status, and social services needed were established.

Database Access: After information was collected, the Parent Partner entered into a secured database: parent(s) name, address, phone number, email, child's Name, gender, date of birth, and diagnosis; also noted family needs, total time spent with family and how information was provided to families.

Parent Partner Service Referrals: After the initial interview, patient and care givers were follow-up by phone or during a second visit at CHOG to ensure families received the information requested, determine if they followed through with service referrals, and provide additional services if needed. Subsequently, the Parent Partner decided whether to close the case or if additional follow-up was needed.

\section{Results}

\section{Characterization of clinic population}

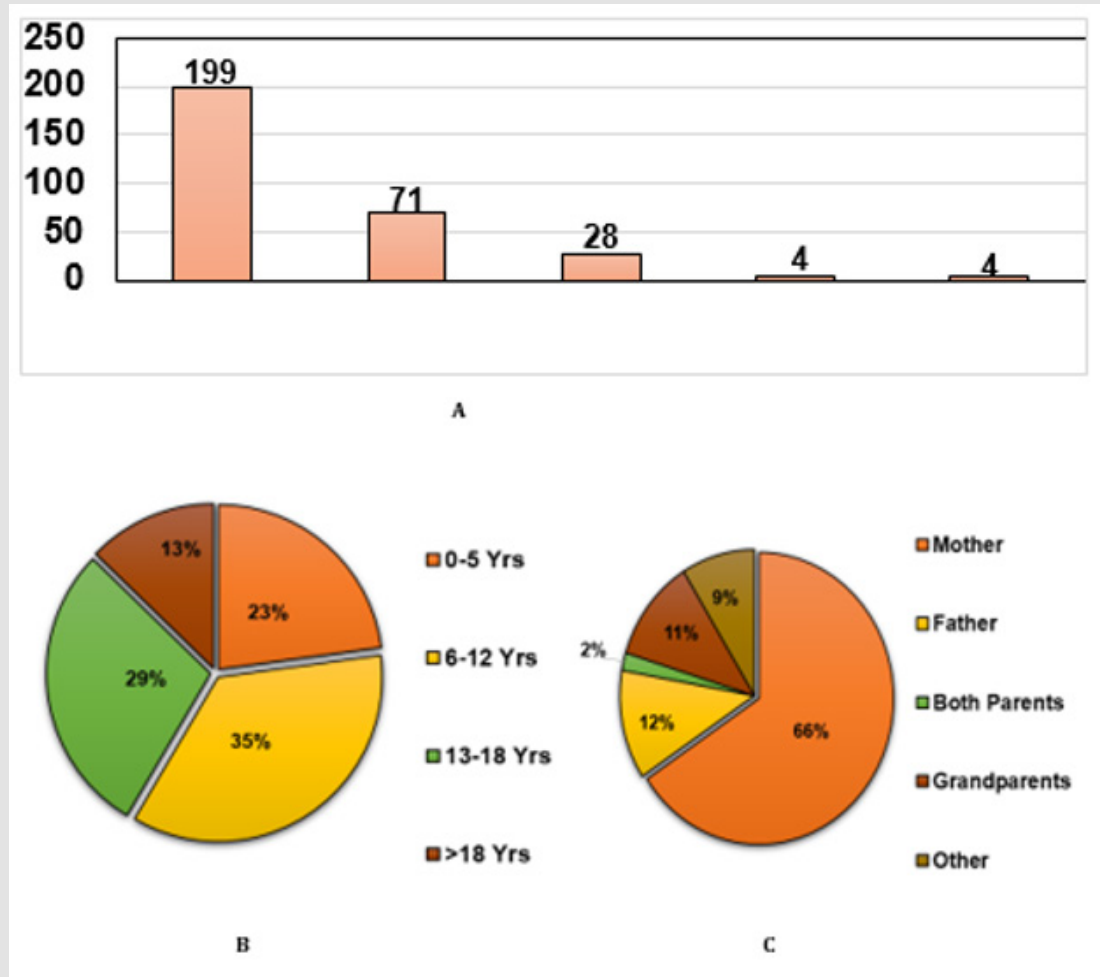

Figure 1: Summary of patient demographics.

A) Shown is the distribution of patients receiving services in the CHOG Comprehensive Sickle Cell Program summarized by sickle cell disease genotypes. Abbreviations: HbSS, sickle cell anemia; HbSC, heterozygous hemoglobin S and hemoglobin C; $\mathrm{HbS}^{+}$-Thal, hemoglobin S- $\beta^{+}$-Thalassemia; HbS $\beta^{0}$-Thal, hemoglobin S- $\beta^{0}$-Thalassemia; Other represent HbCC, hemoglobin $\mathrm{CC}$ and $\alpha-$ Thalassemia.

B) Summary of the age distribution of patients.

C) Shown is the primary caregiver attending clinic visits at the time of Parent Partner interview. The other category represents aunts, godmother, legal guardian, or self. 
The Parent to Parent Program of Georgia was piloted in the Comprehensive Sickle Cell Program (CSCP) at the CHOG where hematology subspecialty services are provided for $\sim 300$ children with SCD. Shown in (Figure 1A) is the breakdown of the different SCD genotypes in our population; 199 patients with homozygous hemoglobin SS disease (HbSS); double heterozygotes included 71 hemoglobin S and $\mathrm{C}(\mathrm{HbSC})$ and 28 hemoglobin $\mathrm{S} \beta+$-Thalassemia (HbS $\beta+$-Thal). There were 4 patients each with $\mathrm{HbS} \beta 0$-Thal or other category (HbCC or $\alpha$-Thalassemia). As shown in (Figure 1B), our age distribution included 0-5 years (23\%), 6-12 years (35\%), 1318 years $(29 \%)$ and $>18$ years $(13 \%)$. The primary caregivers of the patients were $66 \%$ mothers, $12 \%$ fathers, $11 \%$ grandparents, and $9 \%$ others (Figure 1C). The P2P services was highly utilized by caretakers. To establish a viable P2P partnership at CHOG initial onsite training consisting of 101 hours for Parent Partners, 8.5 hours for hematology faculty and staff and 8 hours of parent training was completed (Table 1). The topics covered during training included
$\mathrm{P} 2 \mathrm{P}$ and Me, which is an overview of the programs and services such as Special Needs Database, Roadmap to Success, Supporting Parents, Americans with Disabilities Act, 504 Plans, among others [3]. To introduce the program to the faculty and staff a program description was distributed and the Parent Partner interview occurred after medical service by the physicians in clinic.

P2P of Georgia categorize case levels by how many minutes the Parent Partner spend with the family, gathering demographics, social service needs, responding to the need and follow-up interview. During the study period 545 interviews were conducted of which 104 were follow up visits. The majority of our cases were levels 2 and 3 requiring 15 to 30 minutes (78\%) as shown in Table 1. A few families with significant social services need required initial interviews $\sim 45$ minutes. During the intake interview we collected data on insurance status; the majority of families had State or Federal Assistance program mainly Medicaid (78.1\%), while 9.15\% had private insurance and $12.75 \%$ were self-pay (Table 1 ).

Table 1: Summary of Training and Services Provided by P2P Program.

\begin{tabular}{|c|c|}
\hline P2P Training Participants & Hours \\
\hline Parent Partners ${ }^{1}$ & 101 \\
\hline Hematology faculty and staff ${ }^{2}$ & 8.5 \\
\hline Supporting Parent ${ }^{3}$ & 8 \\
\hline \multicolumn{2}{|l|}{ P2P Training Topics } \\
\hline P2P and Me presentations & 2 \\
\hline ADA \& 504 Plan presentations & 2 \\
\hline Volunteer Training presentations & 1 \\
\hline P2P Onsite Visits & 7 \\
\hline \multicolumn{2}{|l|}{ Services Provided } \\
\hline Case level (minutes) & Number (\%) \\
\hline $1=0-10$ & $61(11.19)$ \\
\hline $2=11-15$ & $183(33.58)$ \\
\hline $3=16-30$ & $245(44.95)$ \\
\hline $4=31-45$ & $49(9.00)$ \\
\hline $5=>45$ & $7(1.28)$ \\
\hline Total & $545(100.00)$ \\
\hline Insurance Status & Number (\%) \\
\hline Medicaid & $239(78.10)$ \\
\hline Private $^{4}$ & $28(9.15)$ \\
\hline Self-pay & $39(12.75)$ \\
\hline Types of referrals by Parent Partner & Number $(\%)$ \\
\hline Adaptation and Accessibility & $7(1.10)$ \\
\hline Adult Services & $1(0.16)$ \\
\hline Camps and Caregivers & $31(4.88)$ \\
\hline Community Resources & $254(40.00)$ \\
\hline Early Childhood & $25(3.94)$ \\
\hline Education Services & $152(23.94)$ \\
\hline Healthcare Services & $7(1.10)$ \\
\hline Mental Health and Behavior Services & $0(0.00)$ \\
\hline
\end{tabular}




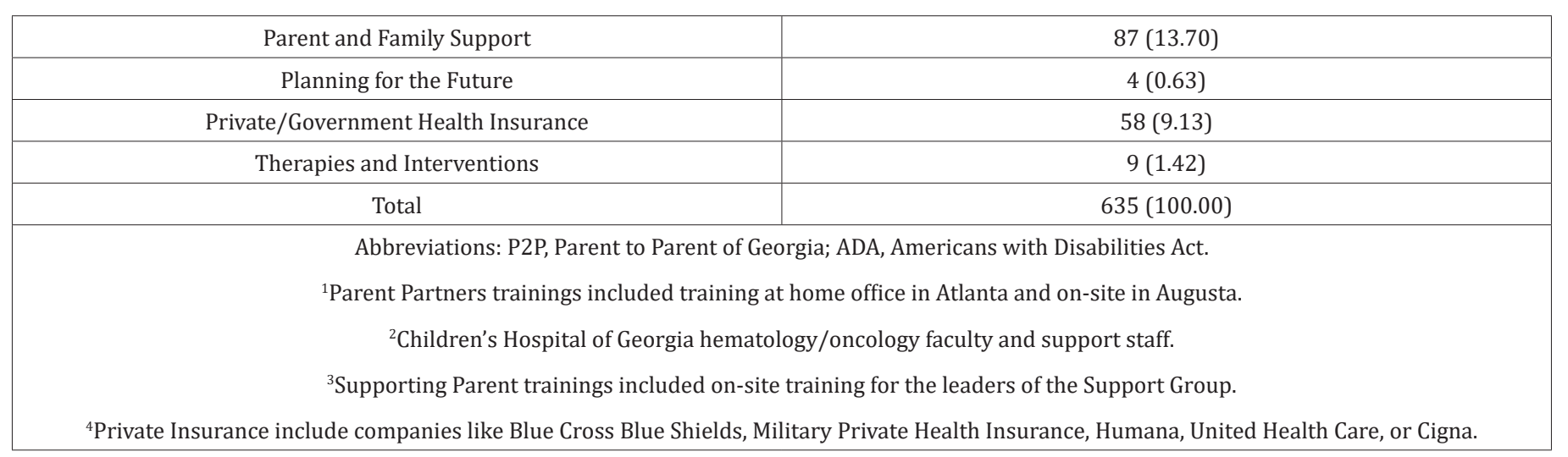

\section{Types of Referrals Requested by Families}

We identified a wide range of services requested by families as shown in Table 1. The most common request from families included P2P of Georgia direct contact information for Community Resources (40\%), Education Services - 504 Plans (23.94\%), Parent and Family Support (13.70\%), and $9.13 \%$ requested Private/Government Health Insurance assistance (Medicaid and SSI issues). The various other referrals made by the Parent Partner are summarized in Table 1.

\section{Discussion}

Due to Sickle Cell Disease being a lifelong disease with no cure as of current date, we in the Augusta University Pediatric Comprehensive Sickle Cell Program found that the P2P program was invaluable to the families. Most families are overwhelmed after getting the diagnosis results that their child has Sickle Cell Disease. It has been bought to our attention, that an understanding of parents' reactions to a newborn infant's diagnosis of sickle cell anemia how they acquire knowledge can identify parent beliefs and preferences about the process of sickle cell education [4]. With that in mind, some families take on the fight-or-flight response. Some parents immediately jump in and fight and do whatever it takes to take of their child. But on the other hand, some parents fall into the flight response. This percent just happens to be higher than we would like. Even though we didn't take a percentage of show rate before this program started, we know it to be common knowledge that it was higher than the healthcare providers/Hematologist would have liked it. One study shows that parents of infants with SCD expressed a high level of fear at the time of notification of a positive screen [4]. Which brings more confirmation that P2P of Georgia services are needed. This was alarming to the Hematologist because when parents decide to take the flight response, there are some basic and specialty care that this vulnerable population needs. When patients miss out on this care, we see more Emergency Department visits, hospital stays, and even mortality.

It is vital for parents of an infant with newly detected Sickle Cell Disease to quickly acquire accurate health information about their child's condition. When parents first learn their infant has Sickle Cell
Disease, they may overcome with anxiety; accurate information can help allay their concerns as well as motivate them to taken actions to improve their child's health. In particular, for Sickle Cell Anemia, parents need to begin to learn about the importance of adhering to recommended prophylaxis, including penicillin, vaccinations, signs, and symptoms of acute exacerbation that require immediate medical attention, and option for therapies such as hydroxyurea [4]. With this pilot study with P2P of Georgia and their services, we have seen the clinical show rates increased, families have become more compliant, and their overall attitude has become positive. Even though in the beginning the Parent Partners had to meet the families where they were in their life and this is why there would be more cases for one family. Because some families needed more help and resources than other families. The highest percentage of cases were needing help with State or Federal Assistance. Mainly, how to start Medicaid and SSI applications.

Or to restart because they had been dropped for numerous reasons. Putting these Parent Partners in place help take some of the tension and stress out of the family's daily life of dealing the SCD. The Parent Partners were someone who worked between the doctors and the families. A liaison between the families and the many program that were in place to help and make their life easier. Parents/caregivers most frequently reported having used the Internet, Sickle Cell pamphlets provided by their primary care physician, and family members as sources of health information [4]. And in this case, what's greater than having an accountable and trained person to contact. The Parent Partners not only have had several hours of training by P2P of Georgia, but they are either a SCD patient or have a child that's diagnosed with Sickle Cell Disease and have accomplished great milestones. Another study revealed that when people with chronic illness learn self-management, their clinic outcome and quality of life improves; and they show lower dependence on healthcare services [5]. This pilot study with P2P of Georgia was a way to show and intervene by putting someone in the family's life to learn and gain skills at an early age. Before this pilot study, there were not any identifying programs that work directly with the families and Hematologist. One other review identifies the important positive effects of educational interventions on 
improving patient's knowledge of Sickle Cell Disease and depression [6]. And individuals who receive higher levels of social support and are more likely to feel as though they have the ability to perform self-care and actually do so to maintain health [B].

With P2P of Georgia it runs very parallel, because it allows and help both parent and child to become more independent and learn what they should do to maintain a healthy life. We do have to keep in mind that children with SCD becomes adults with SCD. And to make the transition as smooth as possible we should make sure that they also learn the skills and resources that is available to maintain good health after transition. The Parent Partners becomes a motivation team for both the parents and caregivers and patients. Many studies and reviews have made it known that various types of social support that could play a role in resiliency in children with SCD (parents, teacher, classmate, and close friend support) to identify the most effective subtype of social support that is associated with resiliency in children with SCD [7]. This pilot study has an actual person (the Parent Partner), in the clinic as a social service support worker to work on cases and observe the inclining of independency and compliant. Once Parent Partners helped the families take care of the basic needs, the parents/caregivers started asking in depth questions. This reflects in the types of referrals by the Parent Partners (Table 1). For an example, inquiring information about planning for the future and adult services. This happened for two reasons. First reason, the majority of the clinic's population was at that time from ages 6 to 12 years. And second reason, was because working with age group showed that they were turning 9 or 10 and the families were showing improvement on doing their own research and showing signs of their independency.

In conclusion, with all resources being available to patients and their families will continue to be independent and be better

ISSN: 2574-1241

DOI: $10.26717 /$ BJSTR.2020.32.005265

Betty S Pace. Biomed J Sci \& Tech Res

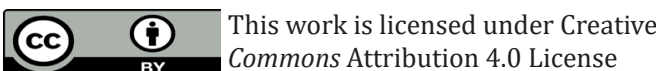

Submission Link: https://biomedres.us/submit-manuscript.php equipped to deal to sickle cell disease on a day to day basics. With a full team, we can also may sure every child has every appointment scheduled, necessary test and scans scheduled, and the resources needed for home. Most of the time a family is overwhelmed with the basic information to help take care of their child. With the assistant of a program like P2P of Georgia in a full partnership with the Pediatric Sickle Cell Program, most families will be independent by the time their child with Sickle Cell becomes a teenager.

\section{Acknowledgement}

First, we thank the children and families that receive care in our program. We thank Natasha Alford, Judi Schweitzer and Ann Sapp for administrative assistance. We acknowledge the Georgia Department of Public Health for support of Telemedicine Program.

\section{References}

1. Parent to Parent USA provides emotional \& informational support for families of children who have special needs.

2. Sickle Cell Disease.

3. www.gadoe.org

4. Lebensburger JD, Grosse SD, Altice JL, Thierry JM, Ivankova NV (2015) Understanding and improving health education among first-time parents of infants with sickle cell anemia in Alabama: a mixed methods approach, J Pediatr Hematol Oncol 37(1): 35-42.

5. Asnani MR, Quimby KR, Bennett NR, Francis DK (2016) Interventions for patients and caregivers to improve knowledge of sickle cell disease and recognition of its related complications. Cochrane Database Syst Rev 10(10): CD011175.

6. Matthie N, Jenerette C, Mc Millan S (2015) Role of self-care in sickle cell disease. Pain Manag Nurs 16(3): 257-266.

7. Sehlo MG, Kamfar HZ (2015) Depression and quality of life in children with sickle cell disease: the effect of social support. BMC Psychiatry 15: 78.

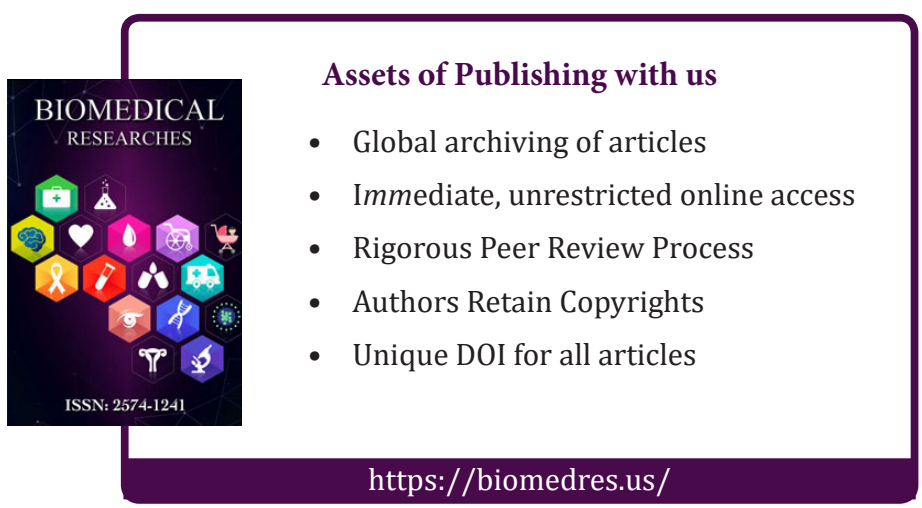

